\title{
Socio-Demographic Health Determinants Are Associated with Poor Prognosis in Spanish Patients Hospitalized with COVID-19
}

\author{
F. Javier Martín-Sánchez, MD, PhD ${ }^{1,2,3}$, Adrián Valls Carbó, MD ${ }^{3}$, Òscar Miró, PhD, MD", \\ Pere Llorens, MD, PhD ${ }^{5}$, Sònia Jiménez, MD, $P h D^{4}$, Pascual Piñera, $M D^{6}$, \\ Guillermo Burillo-Putze, $M D, P h D^{7}$, Alfonso Martín, $M D, P h D^{8}$, \\ Jorge E. García-Lamberechts, $M D, P h D^{1,3}$, Javier Jacob, $M D, P h D^{9}$, \\ Aitor Alquézar, $M D, P h D^{10}$, Carmen Martínez-Valero, $P h D^{3}$, Juan de D. Miranda, $P h D^{11}$, \\ Amanda López Picado, $\mathrm{MD}^{3}$, Juan Pedro Arrebola, $\mathrm{MD}^{12,13,14}$, \\ Marta Esteban López, PhD ${ }^{15}$, Annika Parviainen, $P h D^{16}$, \\ Juan González del Castillo, MD, PhD ${ }^{7,3}$ on behalf of the Spanish Social-Environmental \\ COVID-19 Register, Oscar Miró, Sonia Jimenez, José María Ferreras Amez, \\ Rafael Rubio Díaz, Julio Javier Gamazo del Rio, Héctor Alonso, Pablo Herrero, \\ Noemi Ruiz de Lobera, Carlos Ibero, Plácido Mayan, Rosario Peinado, \\ Carmen Navarro Bustos, Jesús Álvarez Manzanares, Francisco Román, Pascual Piñera, \\ Guillermo Burillo, Javier Jacob, and Carlos Bibiano
}

\begin{abstract}
'Department of Emergency, Hospital Clínico San Carlos, Calle Profesor Martín-Lagos s/n, Madrid, Spain; ${ }^{2}$ Faculty of de Medicine, Universidad Complutense de Madrid, Madrid, Spain; ${ }^{3}$ Institute for Health Research of Hospital San Carlos, Madrid, Spain; ${ }^{4}$ Emergency Department, Hospital Clínic, IDIBAPS, University of Barcelona, Barcelona, Catalonia, Spain; ${ }^{5}$ Emergency Department, Hospital General de Alicante, University Miguel Hernández, Elche, Alicante, Spain; ${ }^{6}$ Emergency Department, Hospital Reina Sofía, Murcia, Spain; ${ }^{7}$ Emergency Department, Hospital Universitario de Canarias, Tenerife, Spain; ${ }^{8}$ Emergency Department, Hospital Severo Ochoa, Leganés, Madrid, Spain; ${ }^{9}$ Emergency Department, Hospital Universitari de Bellvitge, Barcelona, Catalonia, Spain; ${ }^{10}$ Emergency Department, Hospital de la Santa Creu i Sant Pau, Barcelona, Catalonia, Spain; ${ }^{11}$ Risk Modelling Area, Repsol, Madrid, Spain; ${ }^{12}$ Departamento de Medicina Preventiva y Salud Pública, Universidad de Granada, Granada, Spain; ${ }^{13}$ Consortium for Biomedical Research in Epidemiology and Public Health (CIBERESP), Madrid, Spain; ${ }^{14}$ Instituto de Investigación Biosanitaria Granada, Granada, Spain; ${ }^{15}$ Centro Nacional de Sanidad Ambiental, Majadahonda, Instituto de Salud Carlos III, Madrid, Spain; ${ }^{16}$ Instituto Andaluz de Ciencias de la Tierra, Universidad de Granada (UGR-CSIC), Granada, Spain.
\end{abstract}

INTRODUCTION: Social vulnerability is a known determinant of health in respiratory diseases. Our aim was to identify whether there are socio-demographic factors among COVID-19 patients hospitalized in Spain and their potential impact on health outcomes during the hospitalization.

METHODS: A multicentric retrospective case series study based on administrative databases that included all COVID-19 cases admitted in 19 Spanish hospitals from 1 March to 15 April 2020. Socio-demographic data were collected. Outcomes were critical care admission and inhospital mortality.

RESULTS: We included 10,110 COVID-19 patients admitted to 18 Spanish hospitals (median age 68 (IQR 5480) years old; $44.5 \%$ female; $14.8 \%$ were not born in Spain). Among these, 779 (7.7\%) cases were admitted to critical care units and 1678 (16.6\%) patients died during the hospitalization. Age, male gender, being immigrant, and low hospital saturation were independently associated with being admitted to an intensive care unit. Age, male

F. Javier Martin-Sánchez and Adrián Valls Carbó contributed equally to this manuscript and should be considered first author

Received September 30, 2020

Accepted December 29, 2020

Published online July 8, 2021

gender, being immigrant, percentile of average per capita income, and hospital experience were independently associated with in-hospital mortality.

CONCLUSIONS: Social determinants such as residence in low-income areas and being born in Latin American countries were associated with increased odds of being admitted to an intensive care unit and of in-hospital mortality. There was considerable variation in outcomes between different Spanish centers.

KEY WORDS: COVID-19; in-hospital mortality; intensive care unit admission; socio-demographic factors; health inequalities.

\section{Abbreviations}

ICU

HEI

EDSI

$\mathrm{J}$ Gen Intern Med 36(12):3737-42

DOI: $10.1007 / \mathrm{s} 11606-020-06584-6$

(c) Society of General Internal Medicine 2021
Intensive care unit

Hospital Experience Index

Emergency Department Saturation Index 


\section{INTRODUCTION}

In the mid-nineteenth century, based on the typhus epidemic in Upper Silesia and cholera and tuberculosis outbreak in Berlin, Rudolf Virchow developed the theory that social circumstances allow the spread of illnesses. In his own words "[...] crowd diseases point everywhere to deficiencies in society". ${ }^{1}$

More than 100 years later, the first coronavirus disease2019 (COVID-19) case was reported in Wuhan (Hubei, China), with subsequent worldwide spread. ${ }^{2}$ Spain has been one of the most affected countries with high rates of cases (estimated in more than $5 \%$ of population in seroprevalence studies) ${ }^{3}$ and mortality by the spring period $2020 .^{4-6,7,8}$

Social vulnerability is defined by social, economic, demographic, and geographic characteristics and determines the risk exposure and the community capacity to respond and recover from disasters. ${ }^{9}$ It has been widely proven that social determinants can affect health ${ }^{10,11}$ and infectious diseases are a great example on how social vulnerability can influence health outcomes. $^{12,13}$

Recent studies have shown that black, Latino, and native American communities in the USA have been disproportionately impacted by COVID-19 with higher incidence and mortality. ${ }^{14-16}$ These differences have been seen in Spain, where the incidence in the poorest neighborhoods was 2.5 times greater compared with the richest ones. ${ }^{17}$ Incidence and mortality variation may reflect health inequalities and the social determinants in a country with high rates of inequity, supporting the association between social vulnerability and prognosis in COVID19. ${ }^{9}, 15,18$

Health care equity and socio-demographics determinants such as age, gender, ethnicity, level of education, economic status, and characteristics of the area where subjects live may have a significant influence on their health status and outcomes. ${ }^{19}$ As Virchow suggested, pandemics disproportionately affect the poorest and most disadvantaged areas. ${ }^{20}$

Thus, social determinants of health and health care system disparities should be included as part of pandemic research priorities, public health goals, and policy implementation, ${ }^{21}$ because those determinants can affect how epidemics impact these populations.

Although the Spanish health care system is universal and accessibility is theoretically guaranteed to everyone, there is little information about the effect of social determinants in health outcomes among patients in Spanish hospitals during the COVID-19 pandemic. The objective of the present study was to determine whether sociodemographic factors of COVID-19 patients hospitalized in centers of different regions in Spain impacted hospitalization outcomes.

\section{METHODS}

\section{Study Design and Patient Selection}

This is a multicentered, retrospective case series study based on administrative data bases that included all COVID-19 patients $\geq 18$ years admitted to 18 Spanish centers from 1 March to 15 April 2020. The period of study corresponded to the peak of cases in Spain during the first phase of the pandemic. $^{22}$ All patients were followed until 1 June 2020. This research was developed following the Helsinki ethical principles declaration for medical research in humans. The protocol was approved by the HCSC Ethics and Clinical Research Committee (Socio-Covid-19 - C.I. 20/370E_COVID).

We selected 18 urban hospitals including all the 17 administrative regions of Spain excepting Balearic Islands (Appendix Figure 1). Two additional centers, one from Madrid and another from Barcelona, were added because these are the largest cities in Spain. We included all patients admitted with a confirmed or high suspicion for COVID-19 during the study period.

\section{Study Variables}

Data were collected from two different sources. Firstly, we used administrative database of hospitals to identify the cases and to obtain data such as age, gender, birth place, residence postal code, length of stay, intensive care unit (ICU) admission, and in-hospital mortality. Each place of birth was grouped into Latin America, Western Countries, Asia, Arabic Countries, and Sub-Saharan Africa (Appendix Table 1). Patients who were not born in Spain were considered as immigrants.

Secondly, we defined residence area as the postal code area where each patient lived. From each residence area, per capita income average (euros/person/year) and population density (persons $/ \mathrm{km}^{2}$ ) were obtained from the National Statistics Institute of Spanish Statistical Office (https://www.ine.es/en/index.htm). These geographical variables were obtained at census section level and then merged into postal code via QGIS (QGIS Development Team (2020). QGIS Geographic Information System. Open Source Geospatial Foundation Project. http://qgis.osgeo.org).

Hospital areas are the smallest level of geographical organization of the hospital system in Spain in which every people living in a certain hospital area have an assigned hospital for their specialized care. Emergent care can be provided by any hospital, although clinical information from patients who do not belong to the hospital area is scarce; therefore, those patients were excluded from the analysis. For each residence area, the percentile of per capita average income, population density, and mean age was calculated in relation with the distribution of all the postal codes of the country.

In addition, we collected hospital characteristics. We calculated a Hospital Experience Index (HEI), which was defined as 
the daily number of COVID inpatients. For each patient, the median HEI during the period of hospitalization was calculated. Emergency Department Saturation Index (EDSI) was defined as the total number of COVID patients who were admitted in the hospital divided by the total number of beds available, multiplied by the new COVID-admitted cases in the hospital presenting to the Emergency Department. For each patient, EDSI was calculated based on the day the patient arrived to the hospital.

Primary outcomes were ICU admission and all-cause inhospital mortality.

\section{Statistical Analysis}

Continuous variables are presented as mean (standard deviation [SD]) or median (interquartile range [IQR]), as appropriate, and categorical variables as numbers and percentages. Comparisons were made using Student's $t$ for normal continuous variables, Wilcoxon signed-rank test for non-normal continuous variables, and chi-square test for categorical variables. Follow-up started at the time of admission. Predictors of outcomes were explored through generalized linear mixed-effects models, using the center as random effect. Measures of association were expressed as odds ratio (OR), with a $95 \%$ confidence interval (CI). We included variables for adjustment based on a $p<0.10$ in the univariable analysis. Statistically significant differences were based on two-tailed comparisons using a $p<0.05$. Data analysis was performed using R statistical software (R Core Team (2018). R: A language and environment for statistical computing. R Foundation for Statistical Computing. Vienna. Austria. URL https://www.R-project.org).

\section{RESULTS}

Among 12,582 hospitalized COVID-19 patients from 18 centers in Spain, 10,110 cases were included in the analysis. We excluded $2472(19.6 \%)$ subjects because they did not belong to the corresponding hospital areas. The characteristics of each hospital included in the study are described in online Appendix Table 2.

\section{Characteristics of Population}

Table 1 shows the characteristics of the population included in the study. The median age was 68 (IQR 54-80) years old and 4500 of them (44.5\%) were female. Among all patients, $1.498(14.8 \%)$ cases were born in countries other than Spain. The most common place of birth among those who were born outside Spain was Latin America (11\%) followed by Western countries (2.2\%). In general, patients who were not born in Spain were younger (69.1 vs $51.4 ; p<0.001)$ and more frequently women $(44 \%$ vs $46.8 \% ; p=0.04)$ compared to Spanish individuals. Regarding data related to the residence area of the patients, median average per capita income was 11,213 (IQR
Table 1 Characteristics of Population Included in the Study

\begin{tabular}{ll}
\hline \hline & $\begin{array}{l}\text { Total }(\mathbf{N}= \\
\mathbf{1 0 , 1 1 0})\end{array}$ \\
\hline $\begin{array}{l}\text { Demographic patient data } \\
\text { Age (years), median (IQR) }\end{array}$ & $68.0(54.0-80.0)$ \\
Gender female, $n(\%)$ & $4500(44.5)$ \\
Place of birth, $n(\%)$ & \\
$\quad$-Spain & $8649(85.7)$ \\
-Western countries except Spain & $173(1.7)$ \\
-Latin America countries & $1110(11.0)$ \\
-Arabic countries & $75(0.7)$ \\
-Asian countries & $46(0.4)$ \\
-Sub-Saharan African countries & $34(0.3)$ \\
$\begin{array}{l}\text { Data related to postal code area where patients live } \\
\text { Average per capita income of postal code areas in }\end{array}$ & $11,213(9584-$ \\
€/person, median (IQR) & $12,451)$ \\
Population density (people/km $\left.{ }^{2}\right)$, median (IQR) & $140(7.5-1281.8)$ \\
Hospital care data & \\
Hospital Experience Index, median (IQR) & $702(289-1337)$ \\
Emergency Department Saturation Index, median & $12.4(2.5-39.8)$ \\
(IQR) & $8(4-13)$ \\
Length of stay, median (IQR) &
\end{tabular}

9.584-12.451) $€ /$ person/year and population density was 140 (IQR 7.5-1282) inhabitants $/ \mathrm{km}^{2}$ ). Table 1 shows these variables categorized into percentiles in relation with the remaining areas of the country. In relation to hospital care data, median length of stay, HEI, and EDSI were 8 (IQR 4-13), 702 (IQR 289-1337), and 12.4 (IQR 2.5$39.8)$, respectively.

\section{Characteristics of the Population Included According to Hospital}

Socio-demographic data of the subjects in each center is shown in Appendix Table 3. There were statistically significant differences between different centers in terms of age, sex, place of birth, median age, per capita income and population density of areas, length of stay, HEI, EDSI, ICU admission, and deaths.

\section{Factors Associated with in-Hospital Mortality}

Amid all patients, 1.678 (16.6\%) patients died during the hospitalization (Table 2). A higher frequency of death was found in patients who were older, male, born in Spain, hospitalized during periods when HEI and EDSI were lower, living in areas with lower average per capita income and population density, and had longer hospitalization (Table 2). Factors independently associated with in-hospital mortality were age, male gender, HEI, and percentile of average per capita income (Table 3). Immigrants shown a non-significant tendency towards higher mortality (OR 1.26 [0.98-1.62]), which only reached statistical significance in Latin American population (OR 1.37 [1.01-1.84]). No interaction between age, sex, and birthplace was found regarding mortality. According to the model, living in the poorest areas of the country increased the risk of death in the same amount as 4.4 (95\% CI 2.7-4.4) years of aging while those who were from Latin American origin 
Table 2 Univariable Analysis by In-Hospital Mortality and ICU Admission Considering Postal Code Areas According to Country Reference

\begin{tabular}{|c|c|c|c|c|c|c|}
\hline & $\begin{array}{l}\text { Survived } \\
(N=8427)\end{array}$ & Died $(N=1678)$ & $p$ & $\begin{array}{l}\text { Non-ICU admitted } \\
(N=9329)\end{array}$ & $\begin{array}{l}\text { ICU admitted } \\
(N=779)\end{array}$ & $p$ \\
\hline Age (years), median (IQR) & $65.0(52.0-77.0)$ & $82.0(74.0-87.0)$ & $<0.001$ & $69.0(54.0-81.0)$ & $64.0(55.0-71.0)$ & $<0.001$ \\
\hline Female gender, $n(\%)$ & $3854(45.7)$ & $644(38.4)$ & $<0.001$ & $4285(45.9)$ & $214(27.5)$ & $<0.001$ \\
\hline Immigrants, $n(\%)$ & $975(22.2)$ & $69(8.3)$ & $<0.001$ & $961(19.6)$ & $83(25.7)$ & 0.010 \\
\hline Income (postal code percentile, IQR) & $0.60(0.29-0.80)$ & $0.58(0.22-0.77)$ & $<0.001$ & $0.60(0.26-0.80)$ & $0.63(0.35-0.81)$ & 0.036 \\
\hline $\begin{array}{l}\text { Postal code median population } \\
\text { density (percentile, IQR) }\end{array}$ & $0.84(0.49-0.94)$ & $0.82(0.49-0.93)$ & 0.224 & $0.84(0.49-0.94)$ & $0.76(0.45-0.92)$ & $<0.001$ \\
\hline $\begin{array}{l}\text { Hospital Experience Index, } \\
\text { median (IQR) }\end{array}$ & $745(302-1392)$ & $503(233-1089)$ & $<0.001$ & $718(300-1351)$ & $346(201-1001)$ & $<0.001$ \\
\hline $\begin{array}{l}\text { Emergency Department Saturation } \\
\text { Index, median (IQR) }\end{array}$ & $12.9(2.9-39.9)$ & $8.7(1.7-29.8)$ & $<0.001$ & $12.95(2.95-41.21)$ & $4.05(0.58-18.64)$ & $<0.001$ \\
\hline Length of stay, median (IQR) & $8.0(5.0-13.0)$ & $6.0(3.0-12.0)$ & $<0.001$ & $7.00(4.00-12.00)$ & $22.00(11.00-42.00)$ & $<0.001$ \\
\hline
\end{tabular}

According to the $R$ statistical software when a $p$ value is less than 0.001 the value obtained is $p<0.001$. If it is strictly necessary to indicate the exact $p$ value we could compute it, but it probably would be in the order of $1 e-4$ which does not provide more information than $<0.001$

had the same risk of death as their Spanish counterparts who were up to 4 years older (95\% CI 2.3-4) (Fig. 1).

\section{Factors Associated with ICU Admission}

During the studied period, $779(7.7 \%)$ cases were admitted to the ICU and 267 (32.3\%) of them died during hospitalization. Table 2 show the univariable analysis. Patients who were younger, male, coming from areas with higher average per capita income and lower population density, hospitalized during periods when HEI and EDSI were lower, and had longer duration of stay were more frequently admitted to the ICU (Table 2). After a multivariable mixed-model analysis, age, male gender, being immigrant, and lower EDSI were independently associated with ICU admission. In addition, interaction between age and birthplace was found, showing an increase in ICU admission in older immigrants (OR 2.0 [1.54-2.71], $p<0.01)$.

\section{DISCUSSION}

Our study highlights the impact of social and demographic factors on the severity of COVID-19 among admitted patients. Living in a low-income area increased the probability of death. Being from Latin American countries increased the likelihood of death and of being admitted to the ICU, after adjustment for age and gender.
Our study also confirms current evidence that older age and male gender are poor prognostic factors. While the degree of experience and saturation impacted outcomes, there was great variability between the different centers.

Our finding that patients living in low resources areas had a higher probability of dying during hospitalization are consistent with other studies which show social vulnerability to be associated with higher COVID-19 infection risk and case fatality. ${ }^{23}$ The excess of cases of COVID-19 cases in vulnerable communities has been explained by the inequities that these populations suffer, including education, income, nutrition, transportation, housing, jobs, environment, and health care, leading to poor health status. $^{18,24-27}$ Socially vulnerable population are more likely to work in essential services where physical distancing is less feasible, ${ }^{28}$ to use public transportation, ${ }^{29}$ and to live in more crowded and polluted areas ${ }^{30,31}$ which is also related to the risk of respiratory disease, ${ }^{32}$ a well-known cause of increased infection risk and fatality in COVID-19. ${ }^{33,34}$

Regarding the place of birth, we found that the mortality and the risk of being admitted to ICU was almost 1.4 and 1.5 times, respectively, higher in those participants who were born in Latin American countries in comparison to Spanish population. Some studies have previously suggested that this population is more likely to have higher rates of pneumonia, hospital admission, and respiratory oxygen support. ${ }^{35}$ Whether this association could be

Table 3 Multivariable Mixed Model for All-Cause Mortality and ICU Admission Considering Postal Code Areas According to Country Reference

\begin{tabular}{|c|c|c|c|c|}
\hline & Mortality (OR, unadjusted) & $\begin{array}{l}\text { Mortality } \\
\text { (adjusted \$) }\end{array}$ & $\begin{array}{l}\text { ICU admission } \\
\text { (OR, unadjusted) }\end{array}$ & $\begin{array}{l}\text { ICU Admission } \\
\text { (OR, Adjusted\$) }\end{array}$ \\
\hline Age (years) & $3.75(3.46-4.07) * * *$ & $4.10(3.74-4.49) * * *$ & $0.76(0.71-0.81) * * *$ & $0.77(0.71-0.83) * * *$ \\
\hline Female gender & $0.74(0.66-0.82) * * *$ & $0.57(0.51-0.64) * * *$ & $0.45(0.38-0.52) * * *$ & $0.44(0.37-0.51) * * *$ \\
\hline Immigrant & $0.32(0.24-0.41)^{* * *}$ & $1.26(0.98-1.62)$ & $1.21(0.99-1.48)$ & $1.28(1.02-1.61)^{*}$ \\
\hline Income & $0.88(0.83-0.93) * * *$ & $0.89(0.82-0.98) *$ & $1.08(1.01-1.17) *$ & $1.08(0.96-1.21)$ \\
\hline $\begin{array}{l}\text { Postal code area median } \\
\text { population density }\end{array}$ & $0.97(0.92-1.02)$ & $1.09(0.98-1.22)$ & $0.88(0.82-0.94) * * *$ & $0.94(0.82-1.07)$ \\
\hline Hospital Experience Index, median & $0.77(0.72-0.81) * * *$ & $0.59(0.53-0.65) * * *$ & $0.71(0.65-0.77) * * *$ & $1.09(0.93-1.26)$ \\
\hline $\begin{array}{l}\text { Emergency Department } \\
\text { Saturation Index, median }\end{array}$ & $0.89(0.84-0.94) * * *$ & $0.93(0.80-1.08)$ & $0.59(0.52-0.66) * * *$ & $0.45(0.36-0.57) * * *$ \\
\hline
\end{tabular}

${ }^{\$}$ Multivariable mixed model for mortality (center-intraclass correlation $=0.05$, median OR 1.49)

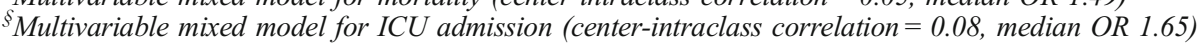

Italicized values indicate statistical significance $(* p<0.05, * * p<0.01, * * * p<0.001)$ 

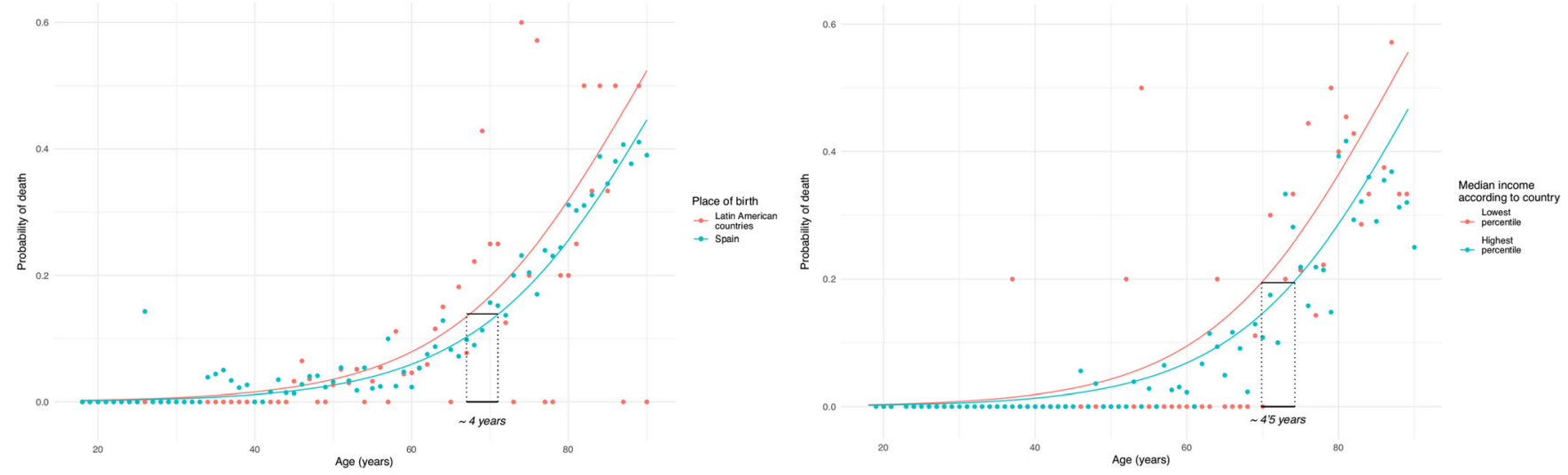

Fig. 1 Probability of death according to the models considering postal code areas according to country reference. Dots represent observed mortality rates for each age and group. Lines represent the predicted probability according to the mode. In the left pannel it is shown how according to our model, the probability of death of an individual born in Latin American countries (LATAM) can be as the one of an spanish born individual 4 years older. In the right pannel is shown how patients who live in the poorer areas of the country have the same mortality as an individual 4.5 years older living in the richer areas

caused to biological or social factors remain unknown, as Latin American population is also the main immigrant population in Spain (41.4\% of foreigners according to the 2019 census).

We found that older age increases the risk of death but decreases the likelihood of ICU admission. Previous studies have found that mortality increases by age, with 5\% mortality between 60 and 69 years, $14.3 \%$ between 70 and 79 years, and $21.3 \%$ among those 80 years and older. ${ }^{4}$ Older people are characterized by physiologic aging changes, multiple age-related comorbid conditions, and polypharmacy. In addition, the immune system of older adults undergoes several age-related changes, collectively termed immune senescence. Also, certain comorbidities such as cardiovascular risk factors, chronic diseases, and cancer have been associated with poor outcomes. All of these factors can contribute to poor health outcomes. ${ }^{36}$

While the disparity in COVID-19 fatality between genders has been reported from the beginning of the pandemic, ${ }^{37,} 38$ few reports have addressed the underlying causes of this disproportion. Multifactorial causes such as hormoneregulated expression of receptor angiotensin-converting enzyme, changes in immune system and lifestyle, and socioeconomic conditions may be contributors to this disparity. ${ }^{39}$

Our study has several limitations. First, the social determinants were estimated from the postal code area where patients lived at the moment of the hospitalization which could introduce some information bias. Second, socio-demographic variables were not adjusted by comorbidity, clinical, nor therapeutic variables and therefore confounding effects remain unmeasured. Third, the diagnosis and admission criteria might vary among the different centers which may influence the outcomes. Fourth, this is a real-life cohort with intervention in which attending physicians followed local protocols. Spain was affected early by COVID-19, and initially, there was little hard evidence on how to effectively treat affected patients. Treatment recommendations for COVID-19 varied during the study period, which may have impacted outcomes over time.

We found that in addition to age and gender, social factors were important prognostic factors in COVID-19. Although this study was performed in a public universal health care system, a large variability in outcomes was documented between Spanish centers which deserves further research.

Supplementary Information The online version contains supplementary material available at https://doi.org/10.1007/s11606-02006584-6.

Acknowledgments: JPA is under contract within the Ramón y Cajal Program (RYC-2016-20155, Ministerio de Economía, Industria y Competitividad, Spain). Investigators of Spanish Social-Environmental COVID-19 Register: Steering Committee: F. Javier Martín-Sánchez, Adrián Valls Carbó, Carmen Martínez Valero, Juan de D. Miranda, Juan Pedro Arrebola, Marta Esteban López, Annika Parviainen, Òscar Miró, Pere Llorens, Sònia Jiménez, Pascual Piñera, Guillermo Burillo, Alfonso Martín, Jorge García Lamberechts, Javier Jacob, Aitor Alquézar, Juan González del Castillo, Amanda López Picado and Iván Núñez. Participating centers: Oscar Miró y Sonia Jimenez. Hospital Clinic de Barcelona. José María Ferreras Amez. Hospital Clínico Universitario Lozano Blesa. Rafael Rubio Díaz. Complejo Hospitalario de Toledo. Julio Javier Gamazo del Rio. Hospital Universitario de Galdakao. Héctor Alonso. Hospital Universitario Miguel de Valdecilla. Pablo Herrero. Hospital Universitario Central de Asturias. Noemí Ruiz de Lobera. Hospital San Pedro de Logroño. Carlos Ibero. Complejo Hospitalario de Navarra. Plácido Mayan. Hospital Clínico Universitario de Santiago. Rosario Peinado. Complejo Hospitalario Universitario de Badajoz. Carmen Navarro Bustos. Hospital Universitario Virgen de la Macarena. Jesús Álvarez Manzanares. Hospital Universitario Rio Hortega. Francisco Román. Hospital Universitario General de Alicante. Pascual Piñera. Hospital Universitario Reina Sofia de Murcia. Guillermo Burillo. Hospital Universitario de Canarias de Tenerife. Javier Jacob. Hospital Universitario de Bellvitge. Carlos Bibiano. Hospital Universitario Infanta Leonor.

Corresponding Author: F. Javier Martín-Sánchez, MD, PhD; Department of Emergency, Hospital Clínico San Carlos, Calle Profesor Martín-Lagos s/n, 28040Madrid, Spain (e-mail: fjjms@hotmail.com).

Authors' Contribution F. Javier Martín Sánchez: Conceptualization, design, analysis, writing - reviewing and editing and assumption of the responsibility for the paper. Adrián Valls Carbó: Conceptualization, design, data collection and curation, analysis, software, figures, and writing - original draft preparation. Òscar Miró: Reviewing. Pere Llorens: Reviewing. Sònia Jiménez: Reviewing. Pascual Piñera: Reviewing. Guillermo Burillo-Putze: Reviewing. Alfonso Martín: Reviewing E. Jorge García-Lamberechts: Reviewing. Javier Jacob: Reviewing. Aitor Alquézar: Reviewing. Carmen Martínez-Valero: Reviewing. Juan de D. Miranda: Reviewing and methodology. Amanda López Picado: Reviewing. Juan Pedro Arrebola: Reviewing. Marta Esteban López: Reviewing. Annika Parviainen: Reviewing. Juan González del Castillo: Data collection and reviewing. 


\section{Compliance with Ethical Standards:}

Conflict of Interest: The authors have nothing to disclose in relationship with this manuscript.

\section{REFERENCES}

1. Meyer H, Ackerknecht EH, Rudolf Virchow. Doctor, Statesman, Anthropologist. Books Abroad. Published online 1955. doi:https://doi. org/10.2307/40094696

2. WHO. Novel Coronavirus (2019-nCoV) Situation Report - 1. WHO Bull. 2020;(JANUARY): 1-7.

3. Pollán M, Pérez-Gómez B, Pastor-Barriuso R, et al. Prevalence of SARSCoV-2 in Spain (ENE-COVID): a nationwide, population-based seroepidemiological study. Lancet (London, England). Published online July 2020. doi:https://doi.org/10.1016/S0140-6736(20)31483-5

4. Romanov BK. Coronavirus disease COVID-2019. Saf Risk Pharmacother. 2020;8(1):3-8. doi:https://doi.org/10.30895/23127821-2020-8-1-3-8

5. Núñez-Gil IJ, Estrada V, Fernández-Pérez C, Fernández-Rozas I Martín-Sánchez FJ, Macaya C. The COVID-19 curve, health system overload, and mortality. Emergencias Rev la Soc Esp Med Emergencias. 2020;32(4):293-295.

6. Gil-Rodrigo A, Miró Ò, Piñera $\mathbf{P}$, et al. Analysis of clinical characteristics and outcomes in patients with COVID-19 based on a series of 1000 patients treated in Spanish emergency departments. Emergencias Rev la Soc Esp Med Emergencias. 2020;32(4):233-241.

7. Martín-Sánchez FJ, González Del Castillo J, Valls Carbó A, López Picado A, Martínez-Valero C, Miranda JD et al. Categorias diagnósticas y resultados a corto plazo en los pacientes con sospecha de COVID-19 atendidos en un servicio de urgencias. Emergencias. 2020;32:242-52.

8. Martín-Sánchez FJ, Del Toro E, Cardassay E, et al. Clinical presentation and outcome across age categories among patients with COVID-19 admitted to a Spanish Emergency Department. Eur Geriatr Med. Published online July 2020:1-13. doi:https://doi.org/10.1007/s41999-020-00359-2

9. Kim SJ, Bostwick W. Social Vulnerability and Racial Inequality in COVID-19 Deaths in Chicago. Heal Educ Behav Off Publ Soc Public Heal Educ. Published online May 2020:1090198120929677. doi:https://doi. org/10.1177/1090198120929677

10. Preda A, Voigt $\mathbf{K}$. The social determinants of health: why should we care? Am J Bioeth. 2015; 15(3):25-36. doi:https://doi.org/10.1080/15265161. 2014.998374

11. Krieger N, Chen JT, Waterman PD, Soobader M-J, Subramanian S V, Carson R. Geocoding and Monitoring of US Socioeconomic Inequalities in Mortality and Cancer Incidence: Does the Choice of Area-based Measure and Geographic Level Matter?: The Public Health Disparities Geocoding Project. Am J Epidemiol. 2002;156(5):471-482. doi:https://doi.org/10.1093/aje/kwf068

12. Semenza JC. Strategies to intervene on social determinants of infectious diseases. Presented at the: July 2010. doi:https://doi.org/10.2807/ese. 15.27.19611-en

13. Semenza JC, Giesecke $\mathbf{J}$. Intervening to reduce inequalities in infections in Europe. Am J Public Health. 2008;98(5):787-792. doi:https://doi.org/ 10.2105/AJPH.2007.120329

14. Fortuna LR, Tolou-Shams M, Robles-Ramamurthy B, Porche M V. Inequity and the disproportionate impact of COVID-19 on communities of color in the United States: The need for a trauma-informed social justice response. Psychol Trauma. Published online June 2020. doi:https://doi. org/10.1037/tra0000889

15. Cyrus E, Clarke R, Hadley D, et al. The impact of COVID-19 on African American communities in the United States. medRxiv Prepr Serv Heal Sci. Published online May 2020. doi:https://doi.org/10.1101/2020.05. 15.20096552

16. Yancy CW. COVID-19 and African Americans. JAMA. 2020;323(19):18911892. doi:https://doi.org/10.1001/jama.2020.6548

17. Baena-Diez JM, Barroso M, Cordeiro-Coelho SI, Díaz JL, Grau M. Impact of COVID-19 outbreak by income: hitting hardest the most deprived. J Public Health (Oxf). Published online August 2020. doi:https://doi.org/10.1093/pubmed/fdaal36

18. Wadhera RK, Wadhera P, Gaba P, et al. Variation in COVID-19 Hospitalizations and Deaths Across New York City Boroughs. JAMA. 2020;323(21):2192-2195. doi:https://doi.org/10.1001/jama.2020.7197

19. Lancet T. Taking urgent action on health inequities. Lancet (London, England). 2020;395(10225):659. doi:https://doi.org/10.1016/S01406736(20)30455-4
20. Takian A, Kiani MM, Khanjankhani K. COVID-19 and the need to prioritize health equity and social determinants of health. Int $\mathrm{J}$ Public Health. Published online May 2020. doi:https://doi.org/10.1007/ s00038-020-01398-Z

21. Abrams EM, Szefler SJ. COVID-19 and the impact of social determinants of health. Lancet Respir Med. Published online May 2020. doi:https://doi.org/10.1016/S2213-2600(20)30234-4

22. Spanish Ministry of Health. No Title. Accessed August 4, 2020. https://www. isciii.es/QueHacemos/Servicios/VigilanciaSaludPublicaRENAVE/ EnfermedadesTransmisibles/Paginas/-COVID-19.-Informes-previos.aspx

23. Nayak A, Islam SJ, Mehta A, et al. Impact of Social Vulnerability on COVID-19 Incidence and Outcomes in the United States. medRxiv Prepr Serv Heal Sci. Published online April 2020. doi:https://doi.org/10.1101/ 2020.04.10.20060962

24. Karaye IM, Horney JA. The Impact of Social Vulnerability on COVID-19 in the U.S.: An Analysis of Spatially Varying Relationships. Am J Prev Med. Published online June 2020. doi:https://doi.org/10.1016/j. amepre.2020.06.006

25. Lee H, Miller VJ. The Disproportionate Impact of COVID-19 on Minority Groups: A Social Justice Concern. J Gerontol Soc Work. Published online June 2020: 1-5. doi:https://doi.org/10.1080/01634372.2020.1777241

26. Tsai J, Wilson M. COVID-19: a potential public health problem for homeless populations. Lancet Public Heal. 2020;5(4):e186-e187. doi:https://doi.org/10.1016/S2468-2667(20)30053-0

27. Mack JW, Paulk ME, Viswanath K, Prigerson HG. Racial disparities in the outcomes of communication on medical care received near death. Arch Intern Med. 2010;170(17):1533-1540. doi:https://doi.org/10. 1001 /archinternmed.2010.322

28. Rufat S, Tate E, Burton CG MA. Social vulnerability to floods: review of case studies and implications for measurement. Int $\mathrm{J}$ Disaster Risk Reduct. 2015;14(4):470-486.

29. Sy KTL, Martinez ME, Rader B, White LF. Socioeconomic disparities in subway use and COVID-19 outcomes in New York City. medRxiv Prepr Serv Heal Sci. Published online May 2020. doi:https://doi.org/10.1101/ 2020.05.28.20115949

30. Ohio State University. Low-income, black neighborhoods still hit hard by air pollution. Science Daily.

31. J C. Air pollution could make the COVID-19 pandemic worse for some people: pollution piles on top of other risk factors. The Verge. Published 2020. Accessed July 9, 2020. www.theverge.com/2020/3/19/21186653/coronavirus-covid-19-air-pollution-vulnerable-lung-disease-pandemic

32. Guarnieri M, Balmes JR. Outdoor air pollution and asthma. Lancet (London, England). 2014;383(9928):1581-1592. doi:https://doi.org/10. 1016/S0140-6736(14)60617-6

33. Wu X, Nethery RC, Sabath BM, Braun D, Dominici F. Exposure to air pollution and COVID-19 mortality in the United States: A nationwide cross-sectional study. medRxiv. Published online January 1, 2020:2020.04.05.20054502. doi:https://doi.org/10.1101/2020.04.05. 20054502

34. Onder G, Rezza G, Brusaferro S. Case-Fatality Rate and Characteristics of Patients Dying in Relation to COVID-19 in Italy. JAMA. 2020;323(18):1775-1776. doi:https://doi.org/10.1001/jama.2020.4683

35. Weng C-H, Saal A, Butt Www, Chan PA. Characteristics and clinical outcomes of COVID-19 in Hispanic/Latino patients in a community setting: A retrospective cohort study. J Med Virol. Published online June 2020. doi:https://doi.org/10.1002/jmv.26196

36. Koff WC, Williams MA. Covid-19 and Immunity in Aging Populations - A New Research Agenda. N Engl J Med. Published online April 2020. doi:https://doi.org/10.1056/NEJMp2006761

37. Guan W-J, Ni Z-Y, Hu Y, et al. Clinical Characteristics of Coronavirus Disease 2019 in China. N Engl J Med. 2020;382(18):1708-1720. doi:https://doi.org/10.1056/NEJMoa2002032

38. Mo P, Xing Y, Xiao Y, et al. Clinical characteristics of refractory COVID19 pneumonia in Wuhan, China. Clin Infect Dis. Published online March 16, 2020. doi:https://doi.org/10.1093/cid/ciaa270

39. Gebhard C, Regitz-Zagrosek V, Neuhauser HK, Morgan R, Klein SL. Impact of sex and gender on COVID-19 outcomes in Europe. Biol Sex Differ. 2020;11(1):29. doi:https://doi.org/10.1186/s13293-020-00304-9

Publisher's Note: Springer Nature remains neutral with regard to jurisdictional claims in published maps and institutional affiliations. 